\title{
Sonhos de esperança em uma Terra Sonâmbula
}

\begin{abstract}
Resumo: Este artigo analisa a forma como Mia Couto, Abstract: This article analyses the manner through em seu livro Terra Sonâmbula, mistura realidade e which Mia Couto, in his book Terra sonâmbula, mixes fantasia de forma mágica, criando um entrelaçamento reality and fantasy in a magic way, creating a entre a tradição e o moderno. Em Terra Sonâmbula, a connection between the tradition and the contemporary. oralidade perpetua a tradição que faz nascer o futuro In Terra sonâmbula, the orality perpetuates the sonhado. Na busca por sua identidade o personagem tradition which brings up the dreamed future. Seeking Muidinga vai adentrando no conhecimento ancestral e his identity, the character Muidinga goes deeper into unindo a tradição à cultura moderna, através da the ancestral knowledge and joins tradition and modern oralidade. culture through orality.
\end{abstract}

Palavras-chave: Mia Couto; Terra Sonâmbula; Keywords: Mia Couto; Terra sonâmbula; orality; oralidade; fantasia. fantasy.

Uma história marcada por guerras e sofrimentos é o que se percebe no imaginário moçambicano. Em 1975, após dez anos de guerra, Moçambique conseguiu sua independência, através de um acordo assinado pela Frente de Libertação de Moçambique (FRELIMO) e Portugal. No entanto, a guerra civil permaneceu até 1992, quando foi assinado o Acordo Geral de Paz, em Roma a 4 de outubro, pelo Presidente da República, Joaquim Chissano, e pelo Presidente da RENAMO (Resistência Nacional Moçambicana). Enfim, uma história entremeada por lutas, e que serve como pano de fundo no romance Terra Sonâmbula (1993), de Mia Couto.

Antônio Emilio Leite Couto, Mia Couto, nasceu na Cidade da Beira, província de Sofala, Moçambique, a 5 de julho de 1955. É formado em Biologia e trabalhou como jornalista. Filho de poeta, Mia Couto nunca abandonou a poesia, pois suas narrativas unem a poesia e a prosa. É um autor engajado nas mudanças de seu país, fez parte da FRELIMO. Autor de mais de 15 livros, sendo que só o primeiro foi de poemas, Raiz de orvalho (1983) ganhou vários prêmios com Terra Sonâmbula (1993), entre eles o de um dos 12 melhores livros de África do século XX.

Em Terra Sonâmbula (1993), vemos um mundo de sonhos que se mistura a uma realidade caótica, de guerras e devastação. Seus personagens caminham entre a certeza e a

\footnotetext{
* Mestre em Literatura Brasileira, Portuguesa e Luso-Africana pela UFRGS. E-mail: carlos-bb@ig.com.br.
} 
dúvida, entre o onírico e a realidade. Sentem-se perdidos e confusos denotando uma situação de abandono, que é a forma como se encontra o país. É nesse espaço limítrofe entre a realidade e a imaginação que vivem os personagens de Terra Sonâmbula (1993).

Temos apenas de fechar os olhos para dormir e aí, no mundo interno do inconsciente, podemos receber todas as noites a visita de formas e forças poderosas do reino mítico. O mito é um sonho coletivo; o sonho, um mito pessoal. (FORD, 1999, p. 46)

Tuahir e Muidinga são os primeiros a serem apresentados como viajantes nesse périplo de aventuras e sonhos, num país destroçado pela guerra. Muidinga, um adolescente e Tuahir um ancião. Na verdade, Muidinga está em busca de seus pais, pois fora salvo da morte por Tuahir e não se recordava de sua infância. Durante a narrativa descobre-se que Tuahir havia salvo Muidinga de ser enterrado vivo, porque havia ingerido um tipo de mandioca que é venenosa e ficara como morto. Nesse sentido, observa-se que o adolescente empreende uma viagem iniciática, conduzido pelo mais velho, Tuahir, pois nos ritos de iniciação, segundo Van Gennep, o noviço é separado da mãe e, durante o ritual, seu corpo é enfraquecido até a perda da memória, sendo então 'ressuscitado' para iniciar uma nova vida na fase adulta,

o noviço é considerado morto, e permanece morto durante o tempo do noviciado. Este dura um tempo mais ou menos longo e consiste no enfraquecimento corporal e mental do noviço, sem dúvida destinado a fazê-lo perder a memória da vida infantil. (GENNEP, 1978, p. 77)

Muidinga é considerado morto por sua tribo e depois 'ressuscitado' por Tuahir que lhe inicia nos ensinamentos da vida adulta. É interessante observar que a iniciação de Muidinga se dá em etapas, nas quais ele tanto vai sendo ensinado, por Tuahir, quanto vai ensinando. Aos poucos Muidinga vai mesclando a sua cultura que tem com a de Tuahir.

Observe-se que Tuahir não sabia ler nem escrever, enquanto que o garoto sabia. Há uma referência muito explícita a cultura tradicional e a nova imposição da cultura letrada. No entanto, em Terra Sonâmbula (1993) não há uma sobreposição da segunda sobre a primeira, pois se bem observado se verá que, apesar de o letramento estar ligado a Muidinga, este dá continuidade a tradição da oralidade quando conta as estórias dos cadernos de Kindzu a Tuahir. Esse contar é feito ritualisticamente à beira da fogueira, como nas comunidades arcaicas.

Do ponto de vista da produção cultural, a arte de contar é uma prática ritualística, um ato de iniciação ao universo da africanidade, e tal prática e ato são, sobretudo, um gesto de prazer pelo qual o mundo real dá lugar ao momento meramente possível que, feito voz, desengrena a realidade e desata a fantasia. (PADILHA, 1995, p. 15)

Assim, há um reconhecimento da necessidade do novo andar de mãos dadas com o velho; o passado com o presente. Esse reconhecimento da necessidade de união do passado 
com o presente está exposto no trabalho de Laura Padilha (1995) sobre os missossos, um tipo de conto tradicional angolano.

Assim, mesmo que a moral explícita aponte para o futuro, já que o missosso, reconhecendo o valor simbólico do novo para a revitalização do indivíduo e conseqüentemente do grupo aponta-o como desejável, não se pode esquecer que o novo caminhava com o velho, mostrando que só pelo ou com o passado o futuro se pode construir. (PADILHA, 1995, p. 44)

Essa integração do velho ao novo se observa também no capítulo em que é narrada a história de Siqueleto, um ancião que ficara só numa das aldeias abandonadas. Tuahir e Muidinga o encontram porque caem numa armadilha e são salvos por ele. Siqueleto fala a língua local e Muidinga não entende, Tuahir serve de intérprete. Assim, observa-se aqui a dependência do novo ao velho. No final, Siqueleto pede que Muidinga escreva seu nome numa árvore, mostrando agora a dependência do velho ao novo. Logo, esses acontecimentos corroboram para reafirmar o que foi dito: o novo anda de mãos dadas com o velho. Em Terra Sonâmbula (1993), mostra-se que o conhecimento ancestral é necessário para que se possa construir um novo paradigma.

Durante a narrativa, Muidinga e Tuahir viajam pela estrada e encontram um local de parada, um ônibus queimado. Decidem permanecer no ônibus, que é um símbolo da modernidade, do deslocamento; um transporte coletivo, que se encontra sem movimento, contrariando a sua representação para o mundo moderno: "o meio de transporte representa a possibilidade, para o homem, de uma locomoção rápida (que designa o esforço de compensação, o anseio de ganhar espaço perdendo menos tempo)" (SEIXO, 1998, p. 20), caracterizando assim, que na narrativa o que importa é o tempo transcorrido e não o espaço percorrido.

No momento em que chegam ao local onde está o machimbombo, como é chamado o ônibus na narrativa, Muidinga encontra os cadernos de Kindzu. Nestes cadernos, temos uma viagem contada em suas minúcias, a qual Muidinga lê para Tuahir. Segundo IANNI (1990, p.3), "Mesmo os que permanecem, que jamais saem do seu lugar, viajam imaginariamente ouvindo estórias, lendo narrativas, vendo coisas, gentes e signos do outro mundo."

Nos escritos de Kindzu temos uma viagem já concluída que vai sendo desvendada aos poucos. Muidinga e Tuahir ao pararem seu deslocamento real estabelecem o que Maria Alzira Seixo (1998) chama de paragem.

E viagem inclui também a fase de uma dinâmica mais abrangente: andar em viagem significa no fundo parar em algum sítio, deter-se na via, suspender o caminho (para um olhar, um diálogo, uma apreensão, um gesto, uma escrita, a renovação do viático; paragens). (SEIXO, 1998, p. 13) 
Os dois personagens, conforme o que diz Seixo, estabelecem a renovação da viagem na paragem, pois sua viagem pelos cadernos de Kindzu cria um novo vínculo com o real, transmudando-o de tal forma, que Muidinga vê a paisagem ao redor do ônibus se modificando: "De fato, a única coisa que acontece é a consecutiva mudança da paisagem. Mas só Muidinga vê essas mudanças. Tuahir diz que são miragens, frutos do desejo de seu companheiro". (COUTO, 1993, p. 77)

Desejo de mudança, esperança de vida, era isso que Muidinga buscava nos cadernos de Kindzu. Nestes cadernos, o protagonista se acha também numa viagem em busca de transformação. Kindzu quer ser um naparama, um guerreiro mágico, nos cadernos apresenta seu pai, o velho Taímo, que tinha sonhos premonitórios e fantásticos. O velho Taímo morre após a independência de Moçambique. Kindzu, assim como o pai, também tem sonhos que se misturam à realidade. Sonhos que são premonitórios. Ter sonhos, aqui, significa como ter ainda esperança. O sonho está ligado à utopia, ao desejo de mudar. Isso se configura logo nas primeiras páginas de Terra Sonâmbula (1993), pelas epígrafes que abrem o livro.

Se dizia daquela terra que era sonâmbula. Porque enquanto os homens dormiam, a terra se movia espaços afora. Quando despertavam, os habitantes olhavam o novo rosto da paisagem e sabiam que, naquela noite, eles tinham sido visitados pela fantasia do sonho.

Crença dos habitantes de Matimati

O que faz andar a estrada? É o sonho. Enquanto a gente sonhar a estrada permanecerá viva. É para isso que servem os caminhos, para nos fazerem parentes do futuro.

Fala de Tuahir (COUTO, 1993, p. 6)

As duas epígrafes são comprovadas logo em seguida pela abertura do primeiro capítulo que se intitula "A estrada morta" e que na primeira linha se lê: "Naquele lugar, a guerra tinha morto a estrada." (COUTO, 1993, p. 9). Dessa forma, comprova-se ser o sonho o elemento que faz seguir adiante, nele reside a esperança. E a guerra, que mata os sonhos, traz consigo a desesperança e o sentimento de desencanto. Numa terra assolada por esse conflito, seus habitantes já perderam a esperança na vida, por isso deixaram de sonhar. Esse mundo dos sonhos é buscado na narrativa, pois, através da fantasia, Muidinga cria e recria o universo de Kindzu. Vive intensamente cada aventura narrada nos cadernos, a ponto de misturar a realidade e a fantasia; o seu mundo e o de Kindzu. Isso é bastante evidente, no momento em que Muidinga propõe a Tuahir brincarem de Kindzu e seu pai: Tuahir faria o papel do velho Taímo, mas a brincadeira chega ao ponto de se confundir com o real.

E Muidinga se atrapalha em totais confusões. É como se qualquer coisa, lá fundo de seu peito, se estivesse rasgando. E se apercebe que, em seu rosto, desliza o frio das lágrimas. Depois, sente a mão de seu pai lhe afagando a cabeça. Olha o seu rosto e vê que, afinal, seus olhos eram sábios. Foi como se, de repente, toda a bondade dele ficasse visível, redonda. (COUTO, 1993, p. 188) 
Logo, Kindzu é Muidinga e vice-versa, através do relato contado, Kindzu reencontra o pai e com ele se reconcilia, e Muidinga encontra em Tuahir o pai que procurava. A cada momento as narrativas de Kindzu e Muidinga vão se tocando e se entrelaçando. Sente-se esse entrelaçamento a partir do momento em que surge no relato a personagem Farida. Ela aparece nos cadernos de Kindzu, conta a sua história e diz que está a procura de seu filho Gaspar. Kindzu se apaixona por Farida. Levada pelos acontecimentos, Farida se isola em um barco que se encontra encalhado, abandonado, como se fosse um barco fantasma. Nesse navio, os dois se encontram e relatam seus sonhos um para o outro. Esse navio pode simbolizar os sonhos impossíveis, uma vez que se encontra encalhado e abandonado como um navio fantasma: "O navio fantasma simboliza os sonhos, de inspiração nobre mas irrealizáveis, do ideal impossível." (CHEVALIER, 1999, p. 632). Além disso, "a metáfora do barco à deriva, símbolo da morte, representa o sentimento de der (rota) que impregna o modernismo e se acirra no pós-modernismo - a modernidade lato sensu". (LOBO, 1988, p. 123)

Farida pede a Kindzu que encontre seu filho Gaspar, e ele parte novamente para o continente em busca do filho de Farida. Começa então uma outra viagem, agora de resgate. Interessante observar que em ambas as viagens, tanto de Muidinga quanto de Kindzu, há uma vontade de construir uma identidade. Muidinga para isso quer encontrar seus pais, Kindzu quer se tornar um naparama, um guerreiro que poderia lutar por seu povo. Ambos personagens acabam voltando a lugares já percorridos, no entanto, nunca os vêem com o mesmo olhar. Sempre há uma mudança, não no lugar e sim no observador, no viajante. Segundo IANNI (1990, p.19) o viajante "tanto se perde como se encontra, ao mesmo tempo que se reafirma e modifica. No curso da viagem há sempre alguma transfiguração, de tal modo que aquele que parte não é nunca o mesmo que regressa.

Tanto Muidinga, quanto Kindzu vão se transformando durante suas viagens e modificando a maneira como percebem as coisas. Tudo vai se tornando diferente ao olhar de quem, de alguma forma, sofreu uma transformação, uma influência no contato com o outro “A viagem pode ser uma longa faina destinada a desenvolver o eu. [...] Um eu que se move, podendo reiterar-se e modificar-se, até mesmo desenvolvendo a sua autoconsciência; ou aprimorando a sua astúcia." (IANNI, 1990, p. 14). Nada do que foi visto ontem será olhado da mesma forma hoje, porque já não se é mais a mesma pessoa.

Ao avistar a praia de Matimati, comprovei como são nossos olhos que fazem o belo. Meu estado de paixão puxava um novo lustro àquela terra em ruínas. Aquelas visões, dias antes, já tinham estado em meus olhos. Porém, agora tudo me parecia mais cheio de cores, em assembléia de belezas. (COUTO, 1993, p. 127) 
Vidas que se modificam no contato com o outro. A construção da identidade como parte da viagem. Isso é o que se percebe nas páginas de Terra Sonâmbula (1993). Personagens que transitam do sonho para o pesadelo da realidade, que choca e paralisa. Percepções que vão se modificando, à medida que a narrativa avança. O olhar já não é mais o mesmo porque, no caminho, algo foi modificado, não fora, mas dentro do indivíduo que caminha. É o viajante que se modifica e não a paisagem ou o outro.

Quem viaja, larga muita coisa na estrada. Além do que larga na partida, larga na travessia. À medida que caminha, despoja-se. Quanto mais descortina o novo, desconhecido, exótico ou surpreendente, mais liberta-se de si, do seu passado, do seu modo de ser, hábitos, vícios, convicções, certeza. Pode abrir-se cada vez mais para o desconhecido, à medida que mergulha no desconhecido. (IANNI, 1990, p. 18)

Nessa modificação do ser, percebe-se que a tradição é vista como algo necessário para que haja uma perfeita harmonia entre o indivíduo e o meio em que vive. É necessário que se conheça o passado para que se possa interferir no presente. Será através da aliança entre o passado e o presente que o indivíduo poderá construir o seu futuro, sem renegar suas tradições, sua cultura e a sabedoria que foi armazenada em cada pequena partícula da tradição de seu povo. Hoje, devido a globalização, a tendência que se observa é a massificação da cultura. Globalizar, criar um mercado comum, com consumidores que sejam fáceis de serem manipulados pela mídia. Ao mesmo tempo, esse mecanismo, que procura uniformizar, cria separações abissais entre os indivíduos, classificando-os em participantes ativos dessa sociedade globalizada ou marginalizados. Estar à margem, no sentido de não ser um consumidor em potencial, não poder fazer parte da grande ciranda de frustrações que o mercado globalizado procura vender: "A sedução do mercado é, simultaneamente, a grande igualadora e a grande divisora." (BAUMAN, 1998, p. 55). Afinal, o que se vende não são sonhos, mas frustrações.

Nesse sentido, a tradição vem na contramão, mostrando ao indivíduo que a cultura local é primordial nesse mundo globalizado. Preservar as tradições e delas tirar proveito para seu crescimento como indivíduo e, conseqüentemente, como cidadão participante de uma nação, é o que se percebe nas entrelinhas de Terra Sonâmbula (1993). Isso não significa viver no passado, mas conseguir unir as duas pontas que são presente e passado para através delas construir um futuro concreto, real. Logo, Tuahir e Muidinga aparecem aqui como partes de um mesmo círculo, são imprescindíveis um ao outro "O ancião liga o novo ao velho, estabelecendo as pontes necessárias para que a ordem se mantenha e os destinos se cumpram;" (PADILHA, 1995, p. 21). É o passado dando as mãos ao futuro. Muidinga 
representa a inteligência, a esperteza, aquele que detém o conhecimento do novo, vínculo estabelecido com a sociedade moderna do homem branco e capitalista. Tuahir é a continuidade da tradição, representa a sabedoria acumulada através daquela.

Percebe-se nessa polarização mais velho x mais novo, que o primeiro é caracterizado pela sabedoria, enquanto o segundo o é pela esperteza. [...] o novo, por não ter vivido ainda tais 'experiências significativas', configura-se imagisticamente como esperto, enquanto o velho o é como sábio. (PADILHA, 1995, p. 43)

Nesse ponto, fica cabal a importância da oralidade nessa viagem. É ela, a oralidade, o meio pelo qual se realiza a viagem. É através da voz de Muidinga que se dá a história de Kindzu. Em cada linha do romance, percebe-se que o contar é importante, conserva-se a tradição não só no conteúdo, mas também na forma, na estrutura da narrativa. Adentra-se na história de Kindzu em capítulos separados da realidade de Muidinga, narrativas encaixadas que se mesclam através da voz deste. A tradição, portanto, perpassa todo o romance, até mesmo na sua construção. Assim, percebe-se aqui a oralidade como símbolo de preservação de uma tradição, da mesma forma que Laura Cavalcante Padilha (1995) aponta nos missossos de Angola.

A oralidade é, desse ponto de vista, o alicerce sobre o qual se construiu o edifício da cultura nacional angolana nos moldes como hoje se identifica. Praticá-la foi mais que uma arte: foi um grito de resistência e uma forma de auto-preservação dos referenciais autóctones, frente à esmagadora força do colonialismo português. (PADILHA, 1995, p. 17)

A viagem é outro elemento que está sempre presente na narrativa, tanto na iniciação de Muidinga como nos cadernos de Kindzu. São várias viagens. Em seus cadernos, Kindzu empreende uma viagem iniciática, assim como Muidinga ao lê-los. E este, juntamente com Tuahir, viaja nos escritos dos cadernos, e nos ensinamentos de Tuahir, a fim de completar a sua viagem. No final, ainda se tem a viagem de Tuahir para a morte, que é caracterizada de uma forma ritualística, pois Muidinga o coloca em uma canoa para que ele seja levado pelo mar. "A barca é o símbolo da viagem, de uma travessia realizada seja pelos vivos, seja pelos mortos." (CHEVALIER, 1999, p. 121). Poeticamente construída, essa passagem de Terra Sonâmbula (1993) consegue transformar a morte em um momento mágico e sublime ao som do mar e das gaivotas. Liberado desse mundo real, Tuahir agora é embalado pela fantasia que se espalha pelas águas de um mar de sonhos.

As ondas vão subindo a duna e rodeiam a canoa. A voz do miúdo quase não se escuta, abafada pelo requebrar das vagas. Tuahir está deitado, olhando a água chegar. Agora, já o barquinho balouça. Aos poucos se vai tornando leve como mulher ao sabor de carícia e se solta do colo da terra, já livre, navegável. Começa então a viagem de tuahir para um mar cheio de infinitas fantasias. Nas ondas estão escritas mil estórias, dessas de embalar as crianças do inteiro mundo. (COUTO, 1993, p. 235) 
Atente-se que não é o mundo inteiro, mas o "inteiro mundo". A colocação desse adjetivo, antecedendo ao substantivo, tem nessa narrativa uma sutil diferença, que traz um importante significado ao contexto. É um mundo que se faz inteiro ao aliar a fantasia, o sonho, as estórias contadas, a tradição, à realidade circundante do presente mundo globalizado. Ao fazer essa junção, tem-se um mundo completo e não fragmentado, um “inteiro mundo". É nas crianças, que conseguem mesclar a fantasia e a realidade, que reside a esperança desse mundo que se fará inteiro. Nelas é que estão os sonhos de esperança para essa terra escalavrada pela guerra. Então, a viagem empreendida pelos personagens de Terra Sonâmbula (1993) ultrapassa o romance e se configura como uma viagem coletiva. Participa dessa viagem cada leitor que se detenha em suas paragens, na busca dessa individualidade, que se transforma na coletividade da nação.

Entretanto, o caminhante não é apenas um "eu" em busca do "outro". Com frequiência é um "nós" em busca dos "outros". Há sempre algo de coletivo no movimento da travessia, nas inquietações, descobertas e frustrações dos que se encontram, tensionam, conflitam, mesclam ou dissolvem. Pode-se dizer que o indivíduo e a coletividade são levados a necessitar da viagem, seja ela real ou imaginária. (IANNI, 1990, p. 16)

Esse individual que se transforma em coletivo, dentro do romance, parte de um princípio diferente do individualismo globalizante. Neste, o indivíduo se faz único pela competitividade, pela busca da superioridade egocêntrica. Já na viagem que se configura em Terra Sonâmbula, o indivíduo se faz único porque percebe de maneira diferente o mundo ao seu redor, através da interiorização dos costumes de seu povo e, ao mesmo tempo, ao fazer essa interiorização se percebe integrado a essa comunidade, a essa nação: “A viagem é sempre realizada por uma personagem em busca de uma situação de melhoramento para si própria ou para o grupo" (PADILHA, 1995, p. 38).

Estrutura que remete ao conteúdo, as viagens empreendidas por Kindzu e Muidinga correm paralelas para no final se entrelaçarem. Muidinga percebe-se partícipe da narrativa de Kindzu e este toma parte da história de Muidinga. Descobrem-se unidos por um ponto comum: Farida. Muidinga, na verdade, é o filho de Farida, Gaspar, por quem Kindzu procurava. Na narrativa que se encontra nos cadernos, Muidinga lê a visão premonitória de Kindzu, no momento de sua morte, na qual ele, Kindzu, se vê frente a Gaspar e grita seu nome. Nesse momento Muidinga adentra nos cadernos, lê sobre si mesmo na narrativa que conta. A história de Kindzu acaba por influenciar a vida de Muidinga. É neste que foram semeadas as esperanças de continuidade de uma tradição que se vê dilacerada. Em Muidinga se percebe a semente lançada na terra. Seus sentimentos fazem agora parte dessa terra porque 
se sente unido a ela, uma vez que vivenciou, através dos relatos de Kindzu, o encontro com as tradições, com os mitos dessa terra de Moçambique. Percebe-se, então, que Muidinga é a semente plantada nas "páginas de terra" de Kindzu.

\begin{abstract}
Mais adiante segue um miúdo com passo lento. Nas suas mãos estão papéis que me parecem familiares. Me aproximo e, com sobressalto, confirmo: são os meus cadernos. Então, com o peito sufocado, chamo: Gaspar! E o menino estremece como se nascesse por uma segunda vez. De sua mão tombam os cadernos. Movidas por um vento que nascia não do ar mas do próprio chão, as folhas se espalham pela estrada. Então, as letras, uma por uma, se vão convertendo em grãos de areia e, aos poucos, todos meus escritos se vão transformando em páginas de terra. (COUTO, 1993, p. 245)
\end{abstract}

No final dessa viagem, há o encontro do velho com o novo. A tradição que é semeada no futuro. Nasce junto com Muidinga a esperança de um tempo. Um tempo repleto de sonhos, de fantasias, no qual a estrada esteja viva e dê passagem aos sonhadores, viajantes da terra. Muidinga nasce de novo ao descobrir a sua identidade; e Moçambique precisa reafirmar sua identidade descobrindo novamente sua cultura, suas tradições, não deixando morrer o velho em detrimento do novo: ao contrário, fazendo com que toda uma sabedoria do passado seja terreno fértil para receber as sementes do futuro. Nas páginas de Terra Sonâmbula (1993), Mia Couto semeia a esperança de um futuro, no qual Moçambique, seja a terra dos sonhos de cada moçambicano: unidos e fortificados pela tradição, ligados à cultura global. Na fala de Tuahir residia a existência de um conhecimento ancestral, assim como nos cadernos de Kindzu que tem suas histórias reveladas através da fala de Muidinga. Assim, a oralidade representa, na narrativa, o elo de ligação entre a tradição e o moderno, pois Muidinga é partícipe da cultura letrada mas também da cultura que se perpetua pela oralidade. Então, é em Muidinga, que reside a esperança de um futuro de paz e sonhos para essa terra. A criança que une o passado e o presente, através do que lhe contam seus antepassados e através da literatura escrita. Assim como o sonho faz viver a estrada é o contar histórias que cria os sonhos. Mia Couto conta um história em que o personagem sonha, e é sonhado pelo leitor, pelo ouvinte. Tuahir e Muidinga são ao mesmo tempo narrador e ouvinte. Muidinga é também leitor, assim como o leitor de Mia Couto será leitor, ouvinte e sonhador dessa narrativa. São sonhos de esperança alimentados por cada leitor, cada sonhador que se percebe como um ouvinte das histórias contadas pelas personagens, sente-se então a força da oralidade que perpassa a narrativa. É dessa forma, que se percebe, na viagem por essa Terra Sonâmbula, os sonhos de esperança que nascem dessas "páginas de terra". 


\section{Referências}

BAUMAN, Zygmunt. O mal-estar da pós-modernidade. Rio de Janeiro: Jorge Zahar Ed., 1998.

CHEVALIER, Jean \& GHEERBRANT, Alain. Dicionário de símbolos. Rio de Janeiro: José Olympio, 1999.

COUTO, Mia. Terra sonâmbula. São Paulo: Record, 1993.

FORD, Clyde. O herói com rosto africano: mitos da África. São Paulo: Summus, 1999. (Selo Negro).

GENNEP, Arnold Van. Os ritos de passagem. Petrópolis: Vozes, 1978.

IANNI, Octavio. A metáfora da viagem. São Paulo: Cultura Vozes, v. 90, n.2, março/abril 1990.

LOBO, Luiza. A der (rota) na metáfora da navegação, de Jorge de Lima a Ana Cristina César. In: $1^{\circ}$ Congresso ABRALIC, 1988, Porto Alegre. Anais. Porto Alegre: UFRGS, 1988. p.123.

PADILHA, Laura Cavalcante. Entre voz e letra: o lugar da ancestralidade na ficção angolana do século XX. Rio de Janeiro: EDUFF, 1995.

SEIXO, Maria Alzira. Poéticas da viagem na literatura. Lisboa: Cosmos, 1998. 